\title{
Digital Storytelling Viewed though a Post-process Lens: Reflections from the Fulbright-Hays 2010 China Seminar
}

\author{
Martha R. Green, Texas A\&M University, USA \\ Lynne M. Walters, Texas A\&M University, USA
}

\begin{abstract}
Post-process theory asserts that writing is public, interpretive, and situated and considers the larger social and political forces that affect a writer. Writing is viewed as a cultural activity by which writers position and reposition themselves in relation to their own and others' subjectivities, discourses, practices, and institutions. Digital storytelling shifts writing from private to public. This qualitative study investigates the process of constructing and publically sharing digital stories by teachers who participated in the Fulbright-Hays Group Projects Abroad 2010 China Seminar. The digital stories from the China Seminar were examined using Bradley's (1995) three-level framework for evaluating levels of reflection. Raters ranked the digital stories, focusing particularly on the evidence of insights about China and Chinese culture, indications of multiple perspectives, and suggestions of new meaning derived from the reflective process. Links to examples of narrative stories at each stage of reflection are in the paper, which uses postmodern and narrative theory to consider narrative representation as it relates to self-construction and revealing self.
\end{abstract}

Keywords: digital storytelling, qualitative research, post-process theory, reflection

The authors wish to thank the U.S. Department of Education Group Projects Abroad Program for funding the 2010 China Seminar, on which this research is based. 
From papyrus to paper, from tribal chief to talking head, from blazing fire to flickering digital screen, people have used available resources to meet a basic human need by telling their own stories in a public forum. Digital technology has given us a new resource for storytelling. It uses multimedia tools, which can involve any combination of video, sound, photography, painting, drawing, music, following a script that is written and narrated by the author, to tell about a meaningful personal experience.

While anyone with a computer and access to the Internet can create and disseminate a digital story, the technique is most closely associated with education. The goal here is to engage students in authentic learning experiences that provide real world relevance and personal value to the learner within a situated context (Bruner 1996; Brown, Collins, \& Duguid, 1989; Kearney \& Schuck, 2006; Emihovich \& Lima, 1995; Lambert, 2006, Sadik, 2008). Digital storytelling encourages the development of traditional skills associated with writing, such as intentionality, reflection, self-evaluation, and revision (Barnett, 2005; Hofer and Swan, 2006), but it shifts storytelling from private to public by allowing students to construct and "publish' their stories, to become authors. The ability of media to extend beyond our immediate circles and reach beyond our localities or villages (e.g. oral traditions of storytelling) is what makes digital storytelling so exciting, compelling, and completely changes the landscape of how we experience and remember events (van Dijck, 2007). Digital stories become permanent artifacts accessible for personal reflection and critique, and for sharing socially within a community of learners or globally on the Internet. This makes digital storytelling a meaningful strategy for teaching and learning in the $21^{\text {st }}$ century.

Like digital storytelling, post-process theory asserts that writing is public, interpretive, and situated (Trimbur, 1994). Post-process theory extends process pedagogy and shifts the focus of composition studies from thinking about writing as a skill or cognitive process by which the individual writer produces text to consideration of meaning and the larger social and political forces that affect a writer (Dobrin, 1997). Post-process theory represents composition as a cultural activity by which writers position and reposition themselves in relation to their own and others' subjectivities, discourses, practices, and institutions (Trimbur, 1994, p. 109). Writing is seen as a human activity, which reaches into all other areas of human endeavor. 


\section{Paradigm Shifts in Composition Studies}

The teaching of writing has undergone a dramatic change in recent times. In the 1960s, and for many decades before, current-traditional rhetoric pedagogy was dominant in the U.S. It placed emphasis on the composed product, rather than on the composing process or the social intent of the writer. The focus was on the analysis of discourse into words, sentences, and paragraphs, and a strong concern with rules: usage, grammar, spelling and punctuation (Young, 1978 as cited in Matsuda, 2003).

In the 1970s, there was a shift from the traditional product-oriented approach, focusing on the finished composition, to a process-oriented approach which views writing as a complex, nonlinear, recursive, messy, and generative process involving pre-drafting (planning \& rescanning), composing, and revising (Abisamara, 2001). This process approach also involves consideration of purpose and audience and cognizance of the writer's background knowledge. It was asserted that the process-oriented pedagogies could improve instruction, if implemented properly, without totally neglecting the end product. Writing was viewed as a cognitive, multi-stages process, the major dynamic of which was learning through doing (Atkinson, 2003). Many American teachers implemented process pedagogy into their classrooms through the reading-writing workshop methodology (Atwell, 1990; Calkins, 1994; Tompkins, 2007). Writing was seen as a social activity composed of a variety of steps: pre-writing, drafting, peer editing, revising - a recursive process (Olson, 1999). Process pedagogy focused on modeling techniques and both writing and reading were regarded as language skills. On the downside, process writing became a device, and the content of writing was often undervalued (Pullman, 1999).

Trimbur (1994, p. 109) first used the phrase post process as a collective term for what he referred to as the "social turn" in composition studies. Post-process theory asserts that writing is a practice that cannot be captured by a generalized process (Kent, 1999, p. 1). Post-process theory calls for a more collaborative and individualized curriculum that stresses writing as hermeneutic activity, as opposed to writing as a skill set. Composition is considered to be a cultural activity. Reading and writing actively construct, and are centrally implicated within power relations, society, culture and the individual self (Atkinson, 2003). The act of writing is public, interpretive, and situated within a specific context (Kent, 1999). By public, Kent means that writing is a communicative interaction, a public interchange. Writing includes an 
audience, as well as the writer. As an interpretive act, writing is a way of making sense of something; to enter into a relationship of understanding with others. Writing is situated since writers always write from some specific position.

Post-process theory recognizes that writers always come to the moment of writing with beliefs, desires, hopes, and fears about the world (Kent, 1999, p.4). Post-process theory seeks to utilize the life experience that students already possess before they enter the classroom (Heard, 2008). Taylor (2000) states, "A post-process orientation attempts to move beyond an easy unity: the unified self of the individual writer and the universal notion of process which separates writing from the rest of curriculum and the individual student's choice from the conventions of a larger audience (p. 49). Harris (1997) states that post-process theory places interest "in the work of a student at the heart of writing class." Timber (2000) argues that university composition classrooms have neglected the circulation of writing. He contends that writing is more than just turning in a paper. "Neglecting delivery has led writing teachers to equate the activity of composing with writing itself and to miss the complex delivery system through which writing circulates" (Trimbur, 2000, p.190). Trimbur states that delivery should be seen as both ethical and political; a democratic way to circulate ideas, opinions and knowledge and expand the public forums where people can deliberate issues.

\section{Digital Storytelling Viewed Through a Post-Process Lens}

Digital storytelling shifts traditional oral storytelling into secondary orality through the use of digital technology (Ong, 1982). Stories serve as avenues to personal experience, and they are the way that human beings make sense of the world and create a personal reality (Schank, 1990, Bruner, 1987, Davis \& Waggert, 2006). Sharing stories allows students to understand what has happened in the past and to be prepared for what could happen in the future (McDrury \& Alterio, 2003). Secondary orality has striking resemblances to the participatory mystique of oral storytelling that fosters a communal sense with an audience and concentrates on the present moment. Secondary orality, however, is a more deliberate and self-conscious form of orality (Ong, 1982, p. 135). Unlike oral stories, which are subject to varying interpretations and emphasis, digital stories become permanent artifacts, finished products that capture a specific moment in time (Lathem, Reyes, \& Qi, 2006). To write visually is to produce a new form of social text that builds on three modes of discourse: orality, the written text, and the video text (Ulmer, 1998). 
Digital stories are stories of lived experience and social action. "Human beings act toward things on the basis of the meanings that the things have for them" (Blumer, 1969, p. 2). By finding words and images to express personal experiences and share them with others, individuals give voice to experience and shift the representation of experience into a realm of shared objectification (Scarry, 1985). Telling a personal story becomes a social process for making lived experience understandable and meaningful (Ellis \& Bochner, 1992). Subjectivity is situated and linked to political, cultural, and historical contexts (Ellis \&Flaherty, 1992). By making the details of one's life accessible to others in public discourse, personal narratives bridge the dominions of public and private life (Ellis \& Bochner, 1992). Sharing lived experiences organizes our understanding of our past life, our current situation, and our imagined future. This inner life is only accessible through introspection and reflexivity. In contrast, the public dimension of the digital storytelling objectifies personal events. While this is a pleasurable experience for some participants, it causes discomfort, or even pain, for some others as they realize that their work has an audience (Gere, 2001). Bleich's (1995) "pedagogy of disclosure" emphasizes the need for a community that welcomes the diversity and individuality of storytellers.

McComiskey (2000) contends that the post-process theory should be viewed as an extension of the process movement rather than a radical break (p. 37). Flower (1994) advocates a "social cognitive" approach to literacy and composing. Flower offers "an integrated vision of literacy that recognizes that writers need to know discourse conventions as well as strategies, to belong to a community, and still take independent journeys of the mind" (p. 293). "Focusing on the work of students means interesting ourselves in the tensions involved both in the acts of producing and in the products themselves; not on rules" (Harris, 1997 as cited in Taylor, 2000, p. 49). McComiskey says that this kind of negotiated view forms both the theoretical and pragmatic foundation of post-process composition studies that extend rather than reject its own history (McComiskey, 2000).

\section{Research Participants}

Participants in this study were 13 middle school and high school social studies and Mandarin language teachers who voluntarily applied and were accepted into a Fulbright-Hays Group Study Abroad China Seminar in summer 2010. All participants were Caucasian, four males and nine females, one of whom was Hispanic and carried a Mexican passport, with an age 
range between 28 and 51. There also was a great range of international experience. Five teachers had lived in and traveled to many parts of the world (although none of the social studies teachers had been to China). The others had not strayed far, if at all, from their Texas homes.

With the overarching goal of developing the educators' intercultural competence and enhancing their schools' world history/geography/cultures curricula, the Seminar provided opportunities for participants to understand family structures, religion, education, economics, and politics of China and to dispel previously-held stereotypes and myths about China and its people. The participants visited cities across China: Beijing, Kunming, Nanjing, Shanghai, Lijiang, Shangri-la, and Huhehot. Here they came in contact with dominant and minority ethnic groups, many of whom are largely unknown in the U.S.

The National Academy of Education Administration (NAEA) in Beijing organized the China Seminar. The Seminar included classroom visits and lectures by experts in some aspect of Chinese life. There were several small group discussions and presentations involving local educators, comparing schools, pedagogy and curricula in Texas and China.

\section{Methods of Inquiry}

After they returned from the China, teacher-participants were asked to construct individual digital stories based on a meaningful personal experience that had occurred during the 31-day Seminar. None of the participants had written a digital story before this assignment, and they did not receive any training on digital story design beyond a one-page instruction sheet.

Besides the digital stories, participants also kept daily journals, added comments to a weekly journal, were personally interviewed by one of the principal investigators and answered survey questions about how they felt when creating and sharing their digital stories. Some of their statements quoted below were drawn from these other sources.

\section{Data Sources and Analysis Methods}

The digital stories* from the China Seminar were examined using Bradley's (1995) threelevel framework for evaluating levels of reflection. Bradley's original model was based on reflections of a service-learning project; the modifications made for this study better suit the 
evaluation of an intercultural immersion experience. The levels were:

Level 1: Descriptive, observations without insight:

A. Gives examples of observed behaviors or characteristics of the setting, the people and the author, but provides no insight into reasons behind the observation;

B. Observations tend to be one dimensional and conversational or unassimilated repetitions of what others have heard or said;

C. Tends to focus on just one aspect of the situation;

D. Does not examine personal beliefs, which then are treated as "hard" evidence;

*The digital stories discussed in this paper can be viewed by clicking on the title links.

E. May acknowledge different perspectives, but does not discriminate among them.

Level 2: Interpretive and emotive, single perspective:

A. Observations are fairly thorough, although generally not placed in a broader context;

B. Provides a cogent critique from one perspective, but fails to see the broader system and other factors that may make change difficult;

C. Uses both unsupported personal belief and evidence, but is beginning to be able to see the difference between them;

D. Perceives legitimate differences of viewpoint;

E. Demonstrates a nascent ability to interpret evidence

Level 3: Active, situations viewed from many perspectives; actions dependent on context:

A. Views things from multiple perspectives; able to see aspects of the situation and place them in context;

B. Perceives and evaluates conflicting goals within and among individuals;

C. Recognizes that actions are situationally dependent and understands many factors affect choice;

D. Makes appropriate assessment of the decisions made by others and self (Bradley, 1995).

Three raters ranked the digital stories, focusing particularly on the evidence of insights about China and Chinese culture, indications of multiple perspectives, and suggestions of new meaning derived from the reflective process. Of the 13 digital stories four were at Level One, 
six at Level Two, and three at Level Three. The four at Level One were purely descriptive and told from only one perspective, that of the narrator. "The Pecking Order," for example, reports on the author's attempt to cross a busy street in China, where there appears to her to be a "pecking order" of vehicle right-of-way, with pedestrians at the bottom.

Another, "Rice," focuses on the main staple of the Chinese diet, how it is grown throughout the country and used in a "wedding ceremony," performed by a group of Miao people. The author, who served as the "groom," told the story from his perspective as a tourist, treating the experience as pure entertainment, rather than as a reflection of the culture that produced it.

Six of the digital stories were ranked at level 2. The most important element missing in these stories is context. Each author thoroughly examined their memorable personal experience, but did not situate it within the larger political, cultural, or social system in China. For example, "Paparazzi" focused on the Chinese penchant for taking pictures of or with groups of travelers, but did not explain the historical isolation of China that made Western tourists "such a big deal" in the country.

Also at Level Two is "The Squatty Potty Story," a four-minute examination of Chinese hygiene, from the troughs at the roadside "rest stops" to the Western-style facilities at the nicer hotels. It is feel good and funny, but the digital story fails to relate the situation to issues, such as urbanization that has grown faster than the sewer system and the uneven division of resources between the city and the country. And the story is told mostly from a Western perspective, although the author acknowledges that there are health and environmental benefits to the Chinese practices.

Three digital stories showed a high level of insight about Chinese culture and revealed clear manifestations of questioning, comparing, and reflecting on experience. One author, who recalled being a child of the "duck and cover" generation, had trouble reconciling the Red Menace of her early years to the friendliness of the Chinese people, the hospitality of our hosts and the eagerness of locals to interact with those who were so clearly "others."

Another author uses the wall metaphor in her journal and digital story to describe the 
isolation she felt as a foreign guest traveling in China and the experience of realizing a dream. She talks about her excitement at visiting the Great Wall of China, the unexpected diversity of the climbers, and the universality of the experience. "Today was the day. It was the day I climbed the wall. I did it. I climbed to the top. I hung with the younger people. I hung with Arabs and Jews. We all breathed in China and put one foot in front of the other. They smiled on the way down and so did I. I was exhilarated." Later in her video, she refers to an afternoon experience at a park in Nanjing that changed her and her digital story. She was watching retired people dancing, singing, and playing musical instruments when, unexpectedly, a Chinese lady held out her hand and asked this U.S. teacher to dance. "My heart sang and my feet danced. I was mapping my digital story about the lack of a true cross culture exchange, and then I actually get some. That's one story I'm excited to make."

The third digital author's story was about wanting to capture the essence of his China experience in song. He hoped to meet musicians in China and share his passion for folk music. He mentions in his journal and digital story the internal conflict that he experienced due to the highly programmed nature of itinerary and the controlling attitude of our Chinese hosts, who were determined to prevent him from meeting with Chinese musicians.

Although the author is clearly frustrated in his efforts to make contact with Chinese folk musicians, reflection, which occurred during the process of creating the digital story, changed his attitude toward the situation and led him to a global perspective. "When I go to the park," he says in his digital narration, "Chinese people are dancing. Retirees are playing old instruments and playing familiar songs. And then it hits me. I realize that I don't need permission to connect with people. I don't need to have a meeting with a folk music scholar or a famous folk musician to build community."

In what clearly is a celebration of his new perspective, the author concludes,

I will play music whenever and where ever the spirit moves me.......And when I play, Chinese people stop and listen. They tap their feet. When I play in a bar, people come in from the street when they hear me singing in English; when I share folk music, the music of the people. 


\section{Results}

The participants designed and showed their digital stories at workshops and to each other. In personal communications and post-workshop questionnaires, the teachers noted the impact of writing and publically sharing their videos. Their comments revealed a connection between their experience with digital stories and post-process theory. Post-process theory places interest in the work of an author at the heart of writing and looks at both the product and at the act of producing (Harris, 1997). Writing is considered to be a cultural activity that is public, interpretive, and situated (Trimbur, 1994). Timber (2000) contends that circulation of an author's work is an essential part of the writing experience. By making the details of one's life accessible to others in public discourse, personal narratives bridge the dominions of public and private life (Ellis \& Bochner, 1992). Through examination of videos produced by the China Seminar, this study seeks to understand what the experience of producing a digital story and sharing it publically means to individuals experiencing meaningful intercultural interactions. Questioned after viewing all the digital stories, the teacher-participants revealed that meaning was both intrinsic and extrinsic. They enjoyed a writing assignment that provided an opportunity to revisit and reflect on a meaningful, personal life experience. Stories are how individuals recount their histories. Said one, "It was an incredible way of putting so many of my thoughts and feelings on paper. I relive my experience every time I see it."

Digital stories also serve as an organizing principle for human action and a focus for constructing meaning from experience (Bruner, 1986, 1996). "My digital story has become a way to preserve and re-visit the strong sense of connection I felt as I met and observed people on our trip," was one response to the post-workshop survey. Another participant noted in an open-ended survey question the transformative nature not just of the trip, but of the process of creating the digital story. "It was interesting to see how the story changed as I worked on it," she said. "I intended to write about how children are the same all over, but it became something totally different. I was sort of surprised by how the story turned out."

Creating the digital stories allowed Fulbright participants to bring to light identity events and to be present as individuals within the learning community. Sharing a digital story that "served as a metaphor for my whole China trip," provided a forum to communicate critical social views. "I can see how digital storytelling could be a useful tool in that you really have 
to think about what's important," said one teacher when queried about her storytelling experience, "before you commit it to 'file.'"

\section{Conclusion}

McComiskey (2000) explains that the post-process theory should be viewed as an extension of the writing process movement; not as a radical change. Post-process theory focuses attention on the act of writing and the circulation or sharing of the product. Digital storytelling provides a format for writing as a communicative interaction, a public interchange. The digital stories are interpretive acts, and writing the stories became a way of making sense of important life events and a pathway for entering into a relationship of understanding with others.

Several areas of interest stand out in teacher-participants' comments. Many revealed in their communications with the researchers that they felt empowered by the process of constructing a digital story and sharing the videos with peers "and with a close circle of friends, family and students." They indicated, on their questionnaires and in their journals, that they benefited from the reflective process of considering a significant past event and putting that event into a meaningful narrative. Teachers found value in sharing personal stories, in becoming known as individuals within the group, the learning community, and in listening to the stories of others. As one noted in an interview with a researcher,

"Well, to be totally honest, I saw several of our fellow travelers work, and it had already encapsulated my exact sentiment...so I shifted gears and decided to do mine on an experience that was so totally unexpected, different and unique. In doing so, I know that it wasn't what may have been wanted, but it was mine, and it stuck and it made me remember how incredibly wonderful, interesting, cool and unexpected China is!!!

The teachers indicated that they would use digital storytelling to teach writing in future classrooms. "I'm really glad I was forced to complete it as I want my students to make them...some already have."

Post-process theory holds that writing is an interpretive act, a public interchange that is situated within a specific time, place, and rhetorical situation. According to Kent (1999), to 
interpret means to enter into a relationship of understanding with other language users and includes both the reception and the production of discourse (Kent, p. 2). The goal of the China Seminar was to develop educators' intercultural competence through immersion in Chinese culture, history and social environment. Writing and producing digital stories engaged China Seminar teachers in confronting previously held beliefs, reflecting on recent experiences, and determining a narrative approach to revealing new understanding to a public audience. Expressing China experiences to others through words and images was a transformative, hermeneutic act that deepened teachers' level of intercultural competence. It required teachers to examine their own positions and challenge other to interpret and perhaps dispute meaning. Most importantly, the China Seminar participants came to understand that the stories we tell allow us to know ourselves and the positions from which we speak, to enter into a relationship of understanding with others (Ellis \& Flaherty, 1992). 


\section{References}

Abisamara, N. (2001).Teaching Writing: Helping Second Language Writers Experience a Sense of Ownership of their Writing, Fall, http://www.nadasisland.com/teachingwriting.htm

Atkinson, D. (2003). L2 writing in the post-process era: introduction. Journal of Second Language Writing. 12, 3-15.

Atwell, N. (1998). In the Middle: New Understanding About Reading, Writing, and Learning. Portsmouth, N.H.: Boynton/Cook.

Barrett, H. (2005). Researching and evaluating digital storytelling as a deep learning tool. The REFLECT Initiative. Retrieved on January 2, 2007, from http://helenbarrett.com/portfolios/SITEStorytelling2006.pdf

Bleich, D. (1995). Collaboration and the pedagogy of disclosure. College English, 57(1), 4361.

Blumer, H. (1969). Symbolic Interactionism: Perspective and Method. Berkeley: University of California Press.

Brown, J., Collins, A. \& Duguid, P. (1989). Situated cognition and the culture of learning, Educational Researcher, 18(1), 32-42.

Bruner, J. (1986). Actual minds, possible worlds. Cambridge, Mass. Harvard University Press.

Bruner, J. (1987). Life as narrative. Social research. 54(1), 11-32.

Burke, K. (1945). A Grammar of Motives. Berkeley: U of California Press.

Calkins, L. (1986). The art of teaching writing ( $2^{\text {nd }}$ ed). Portsmouth, N.H.: Heinemann.

Carter, K. (1993). The place of story in the study of teaching and teacher education. Educational Researcher. 22(1), 5-12,18.

Davis, M. \& Waggett, D. (2006) Enhancing pre-service teachers' reflective practice via technology competencies and e-portfolio development. Society for Information Technology and Teacher Education. Retrieved on September 10, 2007 from http://www.uvm.edu/pt3/?Page=papers.html\&SM=researchsub.html

Delpit, L. (1988). The silenced dialogue: power and pedagogy of educating other people's children. Harvard Educational Review. 58(3), 280-98.

Dobrin, S. (1997). Constructing Knowledges: The Politics of Theory-Building and Pedagogy in Composition. New York: State University Press. 
Ellis, C. \& Bochner, A. ( 1992). Telling and performing personal stories: The constraints of choice in abortion. In C. Ellis \& M.J. Flaherty (Eds.), Investigating Subjectivity: Research on Lived Experience (p.79-101). Newbury Park, CA: Sage.

Emihovich, C. \& Lima, E. (1995). The many facets of Vygotsky: a cultural historical voice from the future. Anthropology \& Education Quarterly. 26(4), 375-383.

Ellis, C \& Flaherty, M. (1992). Investigating Subjectivity. Newbury Park, CA. Sage Publications.

Emihovich, C. \& Lima, E. (1995). The many facets of Vygotsky: a cultural historical voice from the future. Anthropology \& Education Quarterly. 26(4), 375-383.

Flower, L. (1994). The Constructing of Negotiated Meaning: A Social-Cognitive Theory of Writing. Carbondale, IL: University of Southern Illinois Press.

Freire, P. (1970). Pedagogy of the Oppressed. New York. Continuum.

Gere, A. (2001). Revealing silence: rethinking personal writing. College Composition and Communication, National Council of Teachers of English 53(2), 203-223.

Harris, J. (1997). Teaching Subject: Composition Since 1966. Prentice Hall Studies in Writing Culture. Upper Saddle River, NJ: Prentice Hall.

Heard, M. (2008). What should we do with process theory? Pedagogy: Critical Approaches to Teaching Literature, Language, Composition, and Culture. 8(2), 283-304.

Hofer, M. \& Owings Swan, K. (2006). Digital storytelling: moving form promise to practice. In C. Crawford et al. (Eds.), Proceedings of Society for Information Technology and Teacher Education International Conference, March 19 (pp. 679-684). Chesapeake, VA: AACE.

Kent, T. (1999). Post-Process Theory: Beyond the Writing Process Paradigm. Southern Illinois University Press. Carbondale, Ill.

Kearney, M. \& Schuck, S. (2006). Spotlight on authentic learning: student developed digital video products. Australian Journal of Educational Technology. 22(2), 189-208.

Lambert, J. (2006). Digital Storytelling: Capturing Lives, Creating Community. Berkeley, CA: Digital Diner Press.

Lassonde, C. (2006). "You oughta have my life! The story of Jamie, a resistant writer, Support for Learning, 21(3), 135-140.

Lathem, S., Reyes, C. \& Qi, J. (2006). Literacy autobiography: digital storytelling to capture student voice and reflection. In C. Crawford et al. (Eds.), Proceedings of Society for 
Information Technology and Teacher Education International Conference 2006 (pp. 700-704). Chesapeake, VA: AACE.

Linde, C. (1993). Life Stories: The Creation of Coherence. New York: Oxford University Press.

Lykoff, G. \& Johnson, M. (1980). Metaphors We Live By. Chicago: University of Chicago Press.

Matsuda, P. (2003). Process and post-process: a discursive history. Journal of Second Language Writing. 12, 65-83.

McComiskey, B. (2000). Teaching Composition as a Social Process. Logan, Utah. Utah State University Press .

McDrury, J., Alterio, M. (2003) Learning through Storytelling in Higher Education. London: Kogan-Page.

Miller, S. (1991). Textual Carnivals: The Politics of Composition. Carbondale, IL: Southern Illinois University Press.

Olson, G. (1999). Toward a post-process composition: abandoning the rhetoric of assertion. In T. Kent (Ed)., Post-process theory: Beyond the Writing Process Paradigm (pp. 715). Carbondale, Il.: Southern Illinois University Press.

Ong, W. (1982). Orality \& Literacy: The Technologizing of the Word. New York, NY. Routledge.

Pullman, G. (1999). Stepping yet again into the same current. In Kent 1999: 16-29.

Scarry, E. (1985). Body in Pain. New York, Oxford University Press

Sadik, A. (2008). Digital storytelling: a meaningful technology-integrated approach for engaged student learning. Educational Technology Research and Development. 56, 487-506.

Schank, D. (1990). Tell Me a Story: Narrative and Intelligence. Evanstan, IL. Northwestern University Press.

Taylor, M. (2000). Nancie Atwell's In the Middle and the ongoing transformation of the writing workshop. English Journal. September 2000, 46-52.

Tompkins, G. (2007). Teaching Writing: Balancing Process and Product. (5 ${ }^{\text {th }}$ ed.) Upper Saddle River, NJ: Prentice Hall.

Trimbur, J. (1994). Taking the social turn: teaching writing post-process. College Composition and Communication. 45, 108-118. 
Trimbur, J. (2000). Composition and the circulation of writing. College Composition and Communication. 52(2), 188-219.

Ulmer, G. (1989). Teletheory. New York. Routledge.

van Dijck, J. (2007) Mediated Memories in the Digital Age. Stanford Calif.: Stanford University Press.

Young,R. (1978). Paradigms and problems: needed research in rhetorical invention. In C. R. Cooper \& L. Odell (Eds.), Research on Composing: Points of Departure, (p. 29-48). Urbana, Il. National Council of Teachers of English. 